Research Article

\title{
Study on Dynamic Erosion Behavior of 20\# Steel of Natural Gas Gathering Pipeline
}

\author{
Dongli Lv $\mathbb{D}^{1,2}$ Zhanghua Lian, ${ }^{2}$ Lindong Liang $\mathbb{D},{ }^{1}$ Qichao Zhang, ${ }^{2}$ and Tao Zhang $\mathbb{D}^{2}$ \\ ${ }^{1}$ School of Material Science and Engineering, Southwest Petroleum University, Chengdu 610500, China \\ ${ }^{2}$ School of Oil and Natural Gas Engineering, Southwest Petroleum University, Chengdu 610500, China \\ Correspondence should be addressed to Tao Zhang; zhangt@swpu.edu.cn
}

Received 3 April 2019; Revised 4 June 2019; Accepted 13 June 2019; Published 2 July 2019

Guest Editor: Grzegorz Lesiuk

Copyright (c) 2019 Dongli Lv et al. This is an open access article distributed under the Creative Commons Attribution License, which permits unrestricted use, distribution, and reproduction in any medium, provided the original work is properly cited.

In this paper, a finite element model for the particle-impact target is established for the abrasion erosion failure behavior of $20 \#$ steel used in natural gas gathering pipelines. The JC plastic model and failure criterion are used in the model to simulate the failure and damage of the material, and the reliability of the model was verified by comparison with experimental data. The dynamic behavior of particle erosion was studied by using this model. The changes of energy, stress, and morphology at the microscopic level were analyzed. The influence of particle shape, particle size, impact velocity, and impact angle on the erosion rate of $20 \#$ steel was obtained. The model is further used to study the influence mechanism of stress interference on erosion damage behavior under multiparticle random drop impact.

\section{Introduction}

The phenomenon of sand production in the gas field makes it inevitable to carry tiny solid particle impurities in the gas gathering stage, and these particles can cause continuous erosion and wear damage to natural gas gathering pipelines $[1,2]$. Liu et al. and Pereira et al. carried out erosion research on a horizontal elbow $[3,4]$. Fu and Wang carried out erosion research on a throttle valve [5]. At present, the classical fitting models of experimental parameters are generally used to predict the erosion failure law of pipelines, and most of these models do not consider the influence of material properties on model coefficients. Material properties are the most important factor affecting erosion wear. In addition, the impact parameters of particles, such as erosion velocity, particle shape, and impact angle, are also the primary factors on erosion wear.

With the development of computing technology, it is possible to study the microbehavior of erosion failure of materials with different properties [6-8]. Wang et al. proposed a method of a coupling finite element model and smooth particle dynamics model to study the erosion and failure behavior of particles on ductile materials, and the results were in good agreement with previous work [9]. Takaffoli and Papini used a 2D finite element model to simulate the impact behavior of rhomboid particles on a copper target. Both high distortion element removal and adaptive grid technology were tried to deal with large deformation and distortion elements, and the results showed the effectiveness of the model [10]. Takaffoli and Papini used coupled FEM and smooth particle hydrodynamics (SPH) to investigate the removal mechanism of deformation elements in single particle impacts on ductile materials [11]. Furthermore, three-dimensional models of coupled FEM and SPH were used to study the impact failure behavior of Al6061-T6 materials subjected to rhombohedral particles [12]. Liu et al. used the finite element technology based on Johnson-Cook and failure model to discuss the erosion damage of different shape particles on ductile materials, and the results revealed the rule of the impact of particle shape on the erosion damage [13]. Dong et al. simulated the surface erosion behavior of 6061-T6 aluminium alloy and oxygenfree copper with angular particles by SPH. The J-C model and $\mathrm{J}-\mathrm{C}$ failure criterion were adopted. This method has better simulation effect than the traditional finite element method on large deformation and removal of material [14]. 
Kumar and Shukla established the finite element model of single particle impacting titanium alloy by using the abrasive water jet. The Hashish wear model was adopted, and the influence factors of particle shape were considered on the basis of the Finnie cutting model [15]. Wang and Yang divided 100 spherical particles into 10 groups to impact plastic materials and brittle materials, respectively, and obtained reasonable erosion rate results [9]. ElTobgy et al. found that the erosion rate of the same impacted position tended to be stable with the increase of impact times through the finite element simulation of multiple steel ball particles impacting Ti-6Al-4V, and at least three particles were required to reach this stable point value [16].

Based on the understanding of the microstructure and mechanical properties of 20\# steel, which is commonly used in gas gathering pipelines in southwest China, the failure rules of 20\# steel under particle impact were studied by using the finite element method, providing theoretical support for the prediction of the erosion rule of natural gas gathering pipeline components.

\section{Numerical Model}

2.1. Material Properties. 20\# steel is a common type of pipeline steel, and its chemical composition (mass fraction/\%) is $0.16 \mathrm{C}, 0.19 \mathrm{Si}, 0.36 \mathrm{Mn}, 0.01 \mathrm{Ni}, 0.01 \mathrm{Cr}$, and other Fe and belongs to the high-quality low carbon steel, in which plasticity and toughness are good. The microstructure is typical ferrite and pearlite, distributed in sheets, as shown in Figure 1. The mechanical properties of the target material, such as Poisson's ratio, yield strength, and Young's modulus at a temperature of $20^{\circ} \mathrm{C}$, are given in Table 1 .

2.2. Constitutive Models. In this paper, the Johnson-Cook plastic model is adopted, which can accurately predict the plastic deformation of the impacted target under high strain rate. The equivalent stress depends on the equivalent strain $\bar{\varepsilon}_{\text {p }}$, equivalent strain rate $\dot{\varepsilon}$, and temperature, and the expression is as follows:

$$
\sigma=\left(A+B\left(\bar{\varepsilon}_{\mathrm{p}}\right)^{n}\right)\left[1+C \cdot \ln \left(\frac{\dot{\varepsilon}_{\mathrm{p}}}{\dot{\varepsilon}_{0}}\right)\right]\left[1-\left(\frac{T-T_{\mathrm{r}}}{T_{m}-T_{\mathrm{r}}}\right)^{m}\right],
$$

where $\sigma$ is the equivalent stress, $A$ is the yield strength, $B$ is the hardening modulus, $\bar{\varepsilon}_{\mathrm{p}}$ is the equivalent plastic strain, $n$ is the hardening exponent, $C$ is the strain rate coefficient, $\dot{\varepsilon}_{\mathrm{p}}$ is the strain rate, and $\dot{\varepsilon}_{0}$ is the reference strain rate, usually takes $1.0 \mathrm{~s}^{-1}$. $T$ is the target temperature, $T_{\mathrm{r}}$ is the room temperature, $T_{m}$ is the melting point, and $m$ is the strain rate sensitive index.

The Johnson-Cook failure criterion is derived from the accumulative damage method of equivalent plastic strain based on the element integral point, which takes into account stress triaxiality, strain rate, and temperature effect. The failure parameters are defined as follows:

$$
D=\sum \frac{\Delta \bar{\varepsilon}_{\mathrm{p}}}{\varepsilon_{\mathrm{f}}},
$$

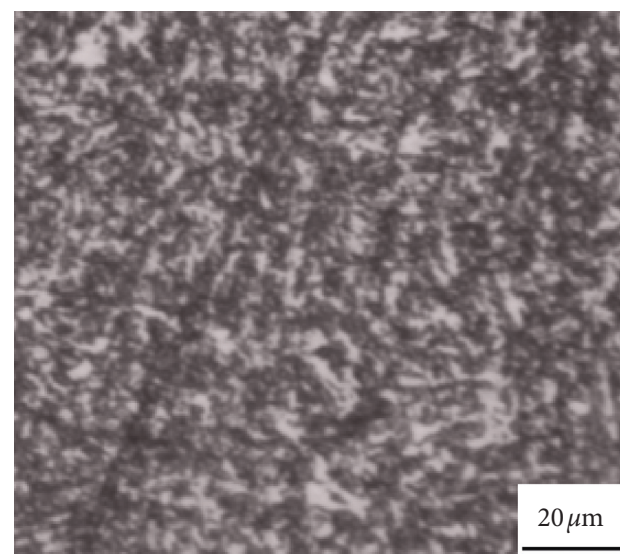

FIgURE 1: Microstructure of 20\# steel.

TABle 1: Mechanical material property

\begin{tabular}{lcccc}
\hline $\begin{array}{l}\text { Density } \\
\left(\mathrm{kg} / \mathrm{m}^{3}\right)\end{array}$ & $\begin{array}{c}\text { Young's } \\
\text { modulus } \\
(\mathrm{GPa})\end{array}$ & $\begin{array}{c}\text { Yield } \\
\text { strength } \\
(\mathrm{MPa})\end{array}$ & $\begin{array}{c}\text { Tensile } \\
\text { strength } \\
(\mathrm{MPa})\end{array}$ & $\begin{array}{c}\text { Poisson's } \\
\text { ratio }\end{array}$ \\
\hline 7850 & 206 & 275 & 410 & 0.3 \\
\hline
\end{tabular}

where $D$ is the failure parameter, $\Delta \bar{\varepsilon}_{\mathrm{p}}$ is the load increases caused by equivalent plastic strain increment, and $\varepsilon_{\mathrm{f}}$ is the failure strain, which is obtained by using the following equation:

$$
\begin{aligned}
\varepsilon_{\mathrm{f}}= & {\left[d_{1}+d_{2} \exp \left(d_{3} \frac{\sigma_{n}}{\sigma}\right)\right]\left[1+d_{4} \ln \left(\frac{\dot{\varepsilon}_{\mathrm{p}}}{\dot{\varepsilon}_{0}}\right)\right] } \\
& \cdot\left[1+d_{5}\left(\frac{T-T_{\mathrm{r}}}{T_{m}-T_{\mathrm{r}}}\right)\right],
\end{aligned}
$$

where $\sigma_{n}$ is the compressive stress. $\sigma$ is the equivalent stress. $\dot{\varepsilon}_{\mathrm{p}}$ is the equivalent strain rate; $\dot{\varepsilon}_{0}$ is the reference strain rate, often takes $1.0 \mathrm{~s}^{-1} ; T$ is the target temperature; $T_{\mathrm{r}}$ is the room temperature; $T_{m}$ is the melting point; and $d_{1} \sim d_{5}$ are the material failure constants.

The failure strain $\varepsilon_{\mathrm{f}}$ and the cumulate of damage are a function of mean temperature, strain rate, and temperature. When the failure parameter $D=1$, it is the initial point of failure initiation.

For the explicit dynamic finite element method, the material is discretized into many finite elements, and all elements $\left(\sum \Delta \varepsilon\right)_{i}$ are calculated by using the dynamic algorithm. For any element $i$ in any time step, as long as the failure parameter $D_{i}=1$, element $i$ will be labeled as failure and enter the damage evolution stage. In this paper, Ti-6Al-4V was used as the target material for simulation, and the results are compared and verified with the published literatures. Then, the target material will be replaced with $20 \#$ steel for research. The specific material parameters are shown in Table 2.

The failure model calculates the critical point of material strength limit, and before the element is deleted, the damage evolution of material needs to be defined. In this paper, the displacement change of linear development is adopted to control the damage: 
TABLE 2: Material parameters.

\begin{tabular}{lcc}
\hline & Ti-6Al-4V & $20 \#$ \\
\hline$\rho\left(\mathrm{kg} \cdot \mathrm{m}^{-3}\right)$ & 4428 & 7840 \\
$E(\mathrm{GPa})$ & 113.8 & 206 \\
$\nu$ & 0.31 & 0.3 \\
$A(\mathrm{MPa})$ & 1098 & 258 \\
$B(\mathrm{MPa})$ & 1092 & 329 \\
$n$ & 0.93 & 0.235 \\
$C$ & 0.014 & 0.0323 \\
$m$ & 1.1 & 1.0 \\
$d_{1}$ & -0.09 & 0.05 \\
$d_{2}$ & 0.27 & 3.44 \\
$d_{3}$ & 0.48 & -2.12 \\
$d_{4}$ & 0.014 & 0.002 \\
$d_{5}$ & 3.87 & 0.61 \\
\hline
\end{tabular}

$$
\dot{d}=\frac{L \dot{\bar{\varepsilon}}^{\mathrm{pl}}}{\bar{u}_{\mathrm{f}}^{\mathrm{pl}}}=\frac{\dot{\bar{u}}^{\mathrm{pl}}}{\bar{u}_{\mathrm{f}}^{\mathrm{pl}}},
$$

where $L$ is the feature length of the element, $\dot{\bar{\varepsilon}}^{\mathrm{pl}}$ is the equivalent plastic strain rate, $\bar{u}_{\mathrm{f}}^{\mathrm{pl}}$ is the failure displacement of element deletion, and $\dot{\bar{u}}^{\mathrm{pl}}$ is the plastic displacement rate. When the value of $\dot{d}$ reaches 1 the element stiffness degradation will automatically be deleted completely.

During the damage evolution process, the element stress is calculated by using the following formula:

$$
\sigma=(1-\dot{d}) \bar{\sigma}
$$

where the parameter $\dot{d}$ has been calculated from the above formula and $\bar{\sigma}$ is the equivalent stress calculated by using the plastic equation assuming that the material has not failed.

2.3. Geometric and Mesh Models. The multiparticle repeated impact finite element model established in this paper is shown in Figure 2. In order to consider the influence of particle corner, three different particle shapes: spherical, tetrakaidecahedron, and triangular prism particles, are adopted. For repeated impacts, a six-particle impact model is set. The initial spacing between particles, initial impact angle, and velocity are all equal to ensure continuous impact on the same position of the target to obtain a stable erosion rate. In order to reduce the influence of boundary effect on simulation results, the target was selected as a rectangular solid of $1200 \mu \mathrm{m} \times 1200 \mu \mathrm{m} \times 360 \mu \mathrm{m}$; that is, the size of the target in the horizontal direction and the thickness direction was 10 times and 3 times of the particle diameter, respectively. Considering that erosion mainly occurs on the contact area in the center, the region of $360 \mu \mathrm{m} \times 360 \mu \mathrm{m} \times 36 \mu \mathrm{m}$ in the center is selected for mesh refinement.

2.4. Boundary Conditions. It is assumed that the solid particles are less deformed in the impact process, and the reference point is the center of mass. In the initial analysis step, the particles and the target were defined as the surface contact, the particle surface was the main surface, the point set in the contact area was the slave surface, and no contact was set between the particles. Normal contact obeys the kinematics contact condition, tangential contact obeys the coulomb friction law, and the mode of slip in contact is the finite slip. The target in the study is equivalent to a small piece embedded in an infinite plate, so all degrees of freedom at the bottom of the target are constrained.

At present, there are four main sources of solid particles in gathering and transportation pipelines: formation particles carried by natural gas, cement, and fracturing proppant produced by drilling, completion, and stimulation processes; rust particles produced by wear and corrosion of pipelines and ground pipelines; and impurity particles settled during pipeline construction, with a maximum diameter of about $200 \mu \mathrm{m}$. According to the working conditions of natural gas gathering pipelines in Sichuan area, the impact velocity selected in simulation is $10 \mathrm{~m} / \mathrm{s}$ to $20 \mathrm{~m} / \mathrm{s}$.

2.5. Model Validation. Yerramareddy and Bahadur carried out erosion experiments on Ti-6Al-4V wafer with the sand blasting machine [17]. The impact particle material was SiC with a diameter of $120 \mu \mathrm{m}$ and density of $3200 \mathrm{~kg} / \mathrm{m}^{3}$. In order to compare with the experiment, the tetrakaidecahedron particle material in the finite element impact model is $\mathrm{SiC}$ with the equivalent diameter of $120 \mu \mathrm{m}$, and the target material is Ti-6Al-4V. The repeated impact particle number is six, and the impact angles are $20^{\circ}, 30^{\circ}, 45^{\circ}, 60^{\circ}$, and $90^{\circ}$ respectively. The time step of simulation is $1.4 \times 10^{-5} \mathrm{~s}$, which is enough to ensure that all particles finish the impact, and the kinetic energy tends to be stable.

After the simulation of 6 times repeated impacts is completed, the equivalent stress distribution on the surface of the target is shown in Figure 3. As can be seen from the figure, some elements are deleted from all angles, and more elements are deleted when impact angles are $20^{\circ}, 30^{\circ}$, and $45^{\circ}$. At a low impact angle, there is a raised lip on the right side of the impact pit, which is consistent with the phenomenon pointed out by cutting theory. However, with the increase of the impact angle, the depth of stress effect increases continuously because the component velocity in the $z$ direction increases with the increase of angle.

Figure 4 shows the statistical change trend of erosion rate at different impact angles. It can be seen that the erosion rate increases first and then decreases. When the impact angle is $30^{\circ}$, the erosion rate reaches its maximum value. When the impact angle increases from $30^{\circ}$ to $90^{\circ}$, the erosion rate decreases rapidly. Compared with the experimental results, it can be seen that the simulated erosion rate is larger than the experimental value, but the development trend of the curve is basically the same, and there is no difference of orders of magnitude in the numerical value. The reason for the difference between the experiment and simulation is that numerical simulation is an ideal case where the sharp corner of each particle contacts the same position of the target. In the experiment, the placement of the particles is relatively dispersed, and a large number of particles are needed to impact to meet the repeated impact at any position of the material 


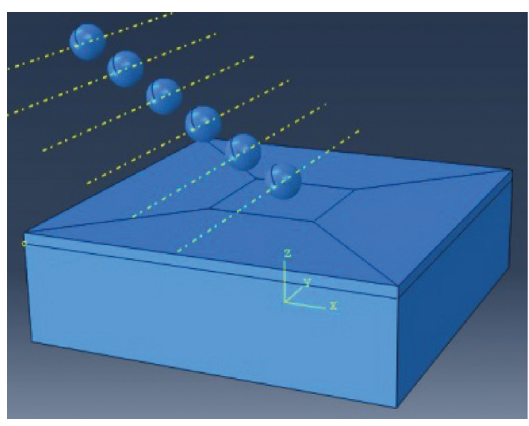

(a)

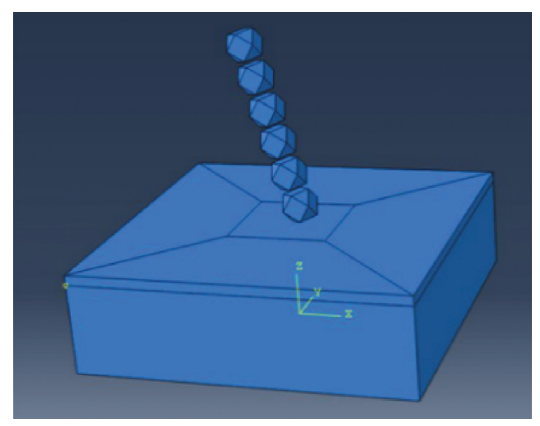

(b)

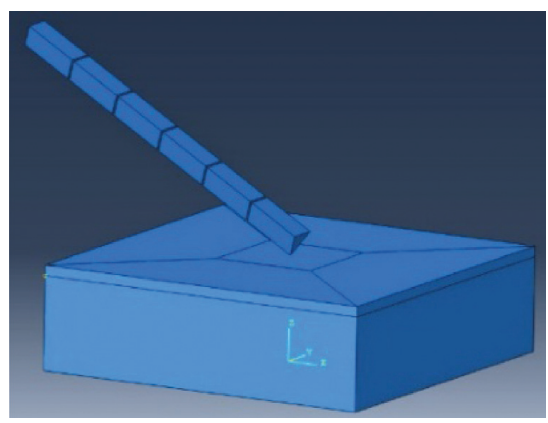

(c)

Figure 2: Geometric model of the impact target. (a) Spherical model. (b) Tetrakaidecahedron model. (c) Triangular prism model.

surface, so the experimental results will significantly be smaller than the simulation results.

\section{Results and Discussion}

3.1. Changes of Stress and Energy during Impact. In this paper, the impact failure morphology of material surface, the energy change in the system, and the movement rule change in the single particle are firstly observed. Particle shape is tetrakaidecahedron, equivalent diameter of $120 \mu \mathrm{m}$, density of $2600 \mathrm{~kg} / \mathrm{m}^{3}$, and impact speed of $15 \mathrm{~m} / \mathrm{s}$ and the impact angles are $15^{\circ}, 30^{\circ}, 45^{\circ}, 60^{\circ}, 75^{\circ}$, and $90^{\circ}$, respectively, in the target material 20\# steel (physical parameters and failure parameters shown in Table 2); the whole analysis step time is $2 \times 10^{-6}$ s.

Figure 5 is a time-dependent curve of the equivalent stress at the center of the erosion zone when particles contact the target at different angles. It can be seen that the equivalent stress of the material is almost over $600 \mathrm{MPa}$, exceeding the strength limit of the material, and the material is already in the state of damage accumulation or failure, but the change trend is different under different impact angles. When the impact angles are $15^{\circ}$ and $75^{\circ}$, respectively, it shows an obvious valley value. When the impact angle is $45^{\circ}$, two peaks and a valley value appear.

This indicates that the plastic stress of the target is constantly changing and related to the failure of the material element. At the beginning of the collision, the sharp part of the particle intrudes and pushes the target material, which causes plastic deformation. In this process, the damage of contact element continuously accumulates until the failure limit value is reached. The element is deleted and the stress is rapidly reduced. If the particles at this time still maintain enough kinetic energy, the subsequent exposed elements will be failed and be deleted, and a peak and a valley value will be formed again, which is like the process of cutting material, indicating that the microcutting phenomenon does exist.

Figure 6 shows the change of kinetic energy of particles with impact angle. It is found that the kinetic energy of particles decreases first and then stabilizes at each impact angle. Some kinetic energy is lost when particles contact the target, which is used to produce plastic deformation on the surface of the target and increase the internal energy of the whole system. When the particle completes the impact and leaves the target, it retains a certain kinetic energy, which corresponds to the stable section of the curve.

The impact time of particles at different impact angles is different. When the impact angle is $15^{\circ}$, the impact time is the longest. When the impact angles are $30^{\circ}$ and $45^{\circ}$, the impact time decreases in turn. When the impact angles are $60^{\circ}, 75^{\circ}$, and $90^{\circ}$, the impact time is close and lower than that of the low angle impact. This is because the particles mainly cut the target at a low impact angle, and the velocity component in the $X$ direction determines the cutting ability. The stronger the cutting action, the longer the particles stay on the target surface. On the contrary, the plastic fluidity of the target in the $Z$ direction is weaker than that in the $X$ direction. The bigger the impact angle, the faster the material enters the hardening stage. Therefore, the impact time at a high impact angle is relative short.

Figure 7 shows the change of kinetic energy consumption of particles under different impact angles. As mentioned above, the amount of kinetic energy consumption can reflect the severity of target erosion. The longitudinal coordinates in the figure represent the ratio of particle kinetic energy consumed to initial kinetic energy. It can intuitively be seen that different impact angles have different effects on erosion. The minimum kinetic energy consumption is $58 \%$ when the impact angle is $15^{\circ}$, and the maximum value is $99 \%$ when the impact angle is $60^{\circ}$. This indicates that serious plastic deformation occurs when the particles are embedded in the target.

3.2. Effect of Particle Velocity. The effect of velocity on erosion rate was studied by using the finite element model of continuous impact of particles on the target. In the simulation, the particle shape is tetrakaidecahedron, the particle equivalent diameter is $120 \mu \mathrm{m}$, and the particle density is $2600 \mathrm{~kg} / \mathrm{m}^{3}$. According to the current velocity range of gas gathering pipeline, five kinds of particle velocities are determined: $10 \mathrm{~m} / \mathrm{s}, 12.5 \mathrm{~m} / \mathrm{s}, 15 \mathrm{~m} / \mathrm{s}, 17.5 \mathrm{~m} / \mathrm{s}$, and $20 \mathrm{~m} / \mathrm{s}$. The impact angles of particles are $30^{\circ}$ and $75^{\circ}$ as representatives of high and low impact angles. It can be seen intuitively from Figure 8 that the number of deleted elements in the target increases with the increase of particle velocity, and the 


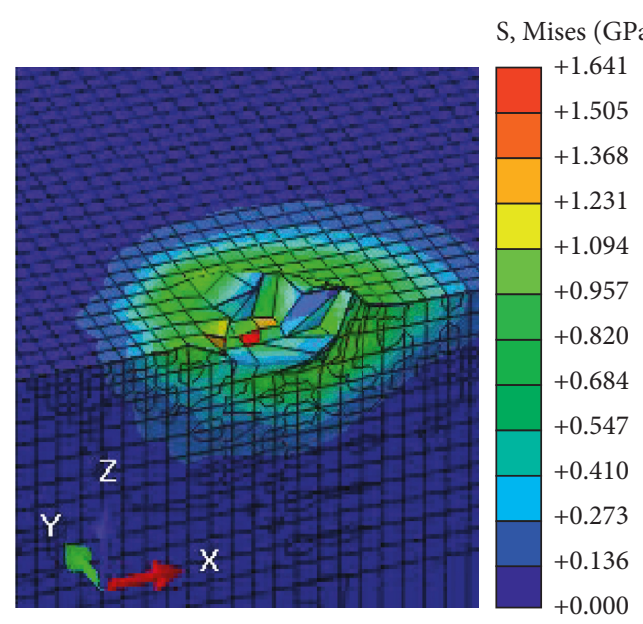

(a)

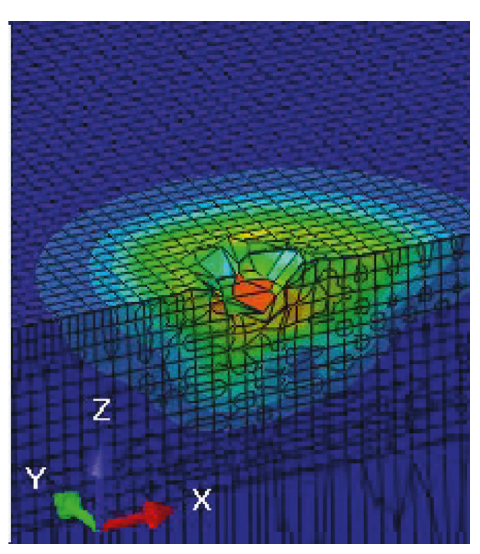

(c)

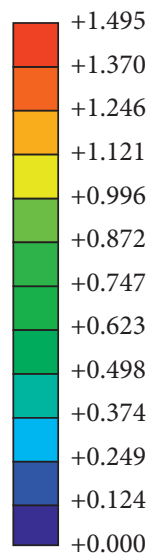

$+0.000$

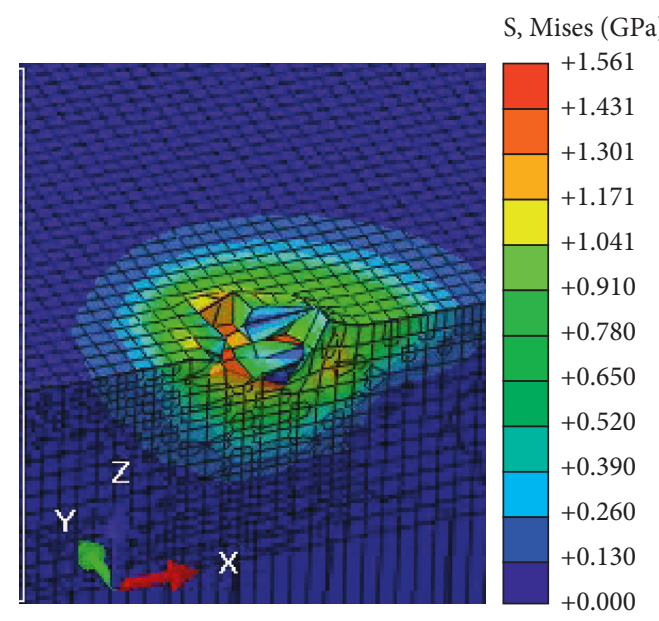

(b)

S, Mises (GPa)

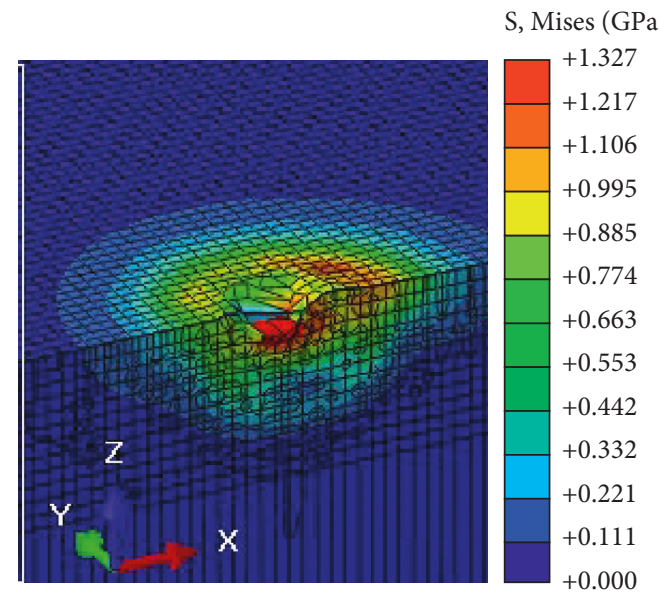

(d)

S, Mises (GPa)

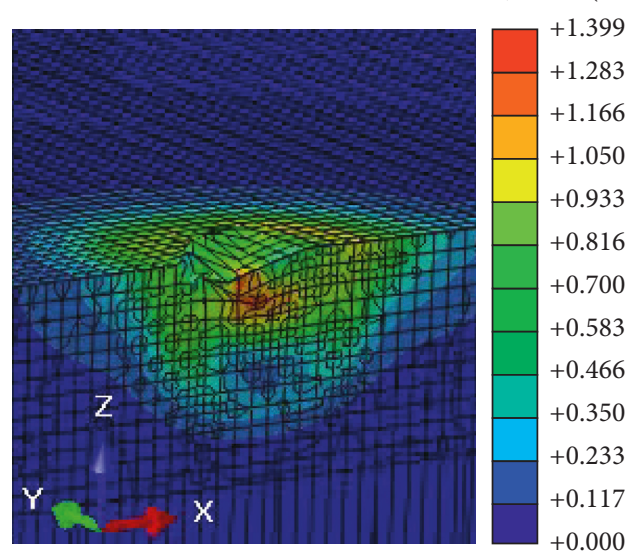

(e)

FIGURE 3: Erosion stress contour of the target material after repeated impacts at different impact angles. (a) $20^{\circ}$, (b) $30^{\circ}$, (c) $45^{\circ}$, (d) $60^{\circ}$, and (e) $90^{\circ}$.

impact damage to the target becomes more and more serious.

Figure 9 shows the increase of the erosion rate under two impact angles in the form of a curve. It can be seen from the figure that the erosion rate increases dramatically with the increase of impact velocity. When the impact angle is $30^{\circ}$ and the velocity increases from $10 \mathrm{~m} / \mathrm{s}$ to $20 \mathrm{~m} / \mathrm{s}$, the erosion rate increases from $0.33 \mathrm{mg} / \mathrm{g}$ to $1.35 \mathrm{mg} / \mathrm{g}$, which is four times the original value. When the impact angle is $75^{\circ}$, the velocity increases from $10 \mathrm{~m} / \mathrm{s}$ to $20 \mathrm{~m} / \mathrm{s}$, and the erosion rate increases 


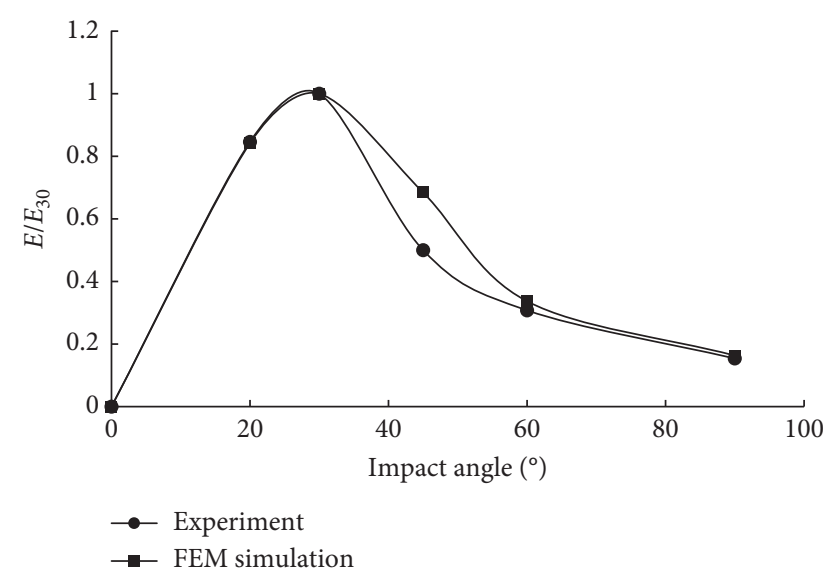

FIgURE 4: Change of the erosion rate with the impact angle.

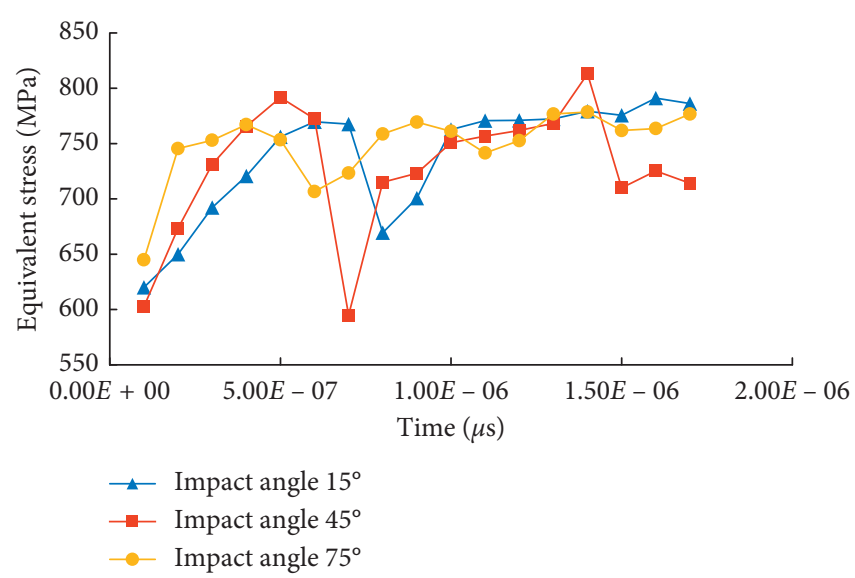

Figure 5: Equivalent stress changes at the erosion center with time.

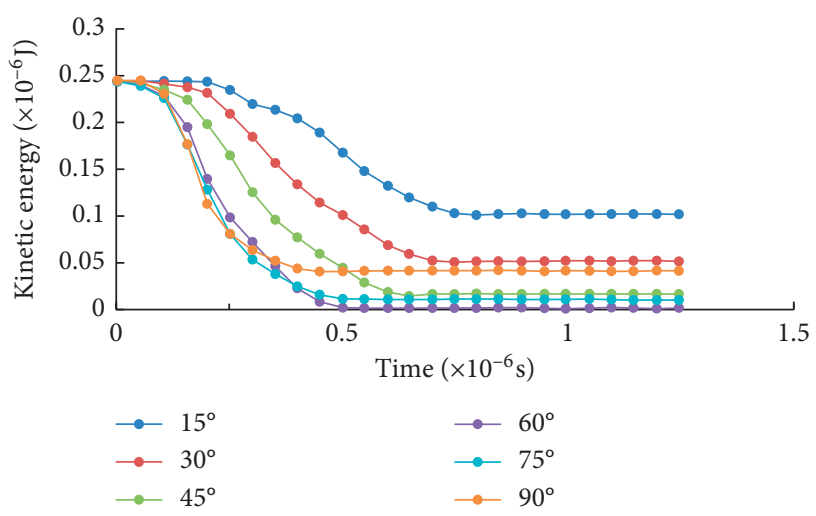

Figure 6: Change of kinetic energy of particles with time.

from $0.28 \mathrm{mg} / \mathrm{g}$ to $1.49 \mathrm{mg} / \mathrm{g}$, which is 5.3 times of the original value. It can be seen that, regardless of the impact angle, the impact velocity is generally low, the erosion rate is very sensitive to the change of impact velocity, and the sensitivity can be seen from the velocity index. Through power function regression of the two angle curves, it is found that the velocity exponent is 2.04 when the impact angle is $30^{\circ}$ and the velocity exponent is 2.41 when the impact angle is $75^{\circ}$. The velocity

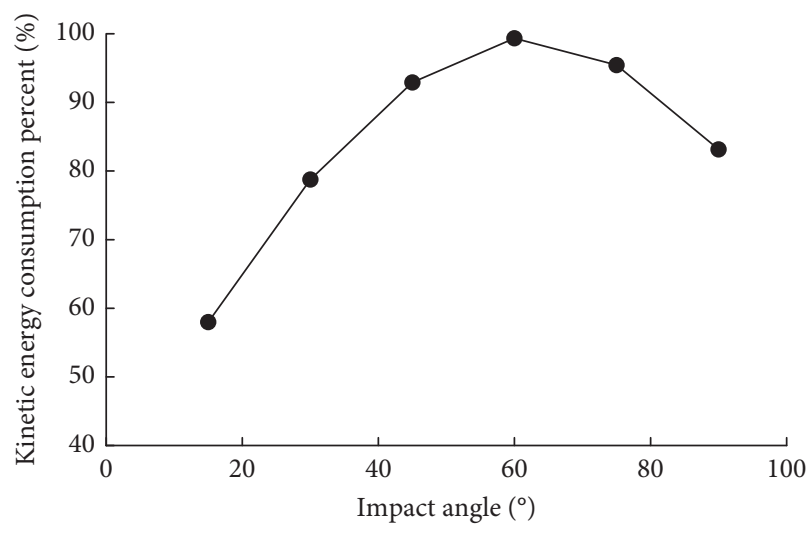

FIgURE 7: Ratio of kinetic energy consumption varies with the impact angle.

index predicted by using the finite element method coincides with the conclusions of the previous studies.

The reason for the velocity index is different in the case of high and low impact angles may be that the contact position of particles changes constantly in the process of continuous impact. At the low impact angle, when the velocity is large enough, the particle tip removes the target surface material by cutting or ploughing, and the impact point of subsequent particles always remains at the end of the cutting groove, which is conducive to lip extrusion but not conducive to lip removal, so the contribution of the increase of kinetic energy to the erosion rate decreases. Deformation and wear occur on material surface under high angle impact as long as the speed is sufficient to cause the plastic deformation. Particle kinetic energy increases rapidly with the increase of impact velocity, and the impact pit deepens and the plastic deformation of the extrusion lip increases. Under the repeated impacting, the material is easier to harden and exfoliate, which makes the erosion rate raise and occur faster, and the speed index is larger.

3.3. Effect of Impact Angle. Similarly, the finite element model of continuous impact of particles on the target material was used to study the impact angle on the erosion characteristics. Other conditions were the same as in 3.2, and the particle velocity was $15 \mathrm{~m} / \mathrm{s}$. The stress of target material surface continuously impacted by particles under different impact angles was calculated. It can be found that serious deformation and failure deletion of elements occur on the target surface, and the stress contour changes obviously with different impact angles. The results show that the peak erosion rate appears at $45^{\circ}$, and the peak erosion rate of ordinary plastic materials occurs at $30 \sim 35^{\circ}$. It is shown that the angle of the peak value of the erosion rate depends on the target material characteristics, and the development trend of the simulated erosion rate curve is to increase first and then decrease.

The simulation results compared with the erosion prediction model established by Finnie [15] is shown in Figure 10. It can be seen that the calculated value of the Finnie 
$\mathrm{S}$, Mises (GPa)
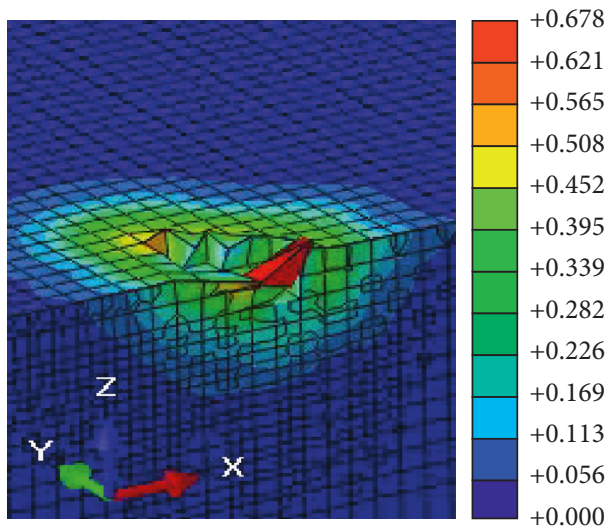

$\mathrm{S}$, Mises $(\mathrm{GPa})$
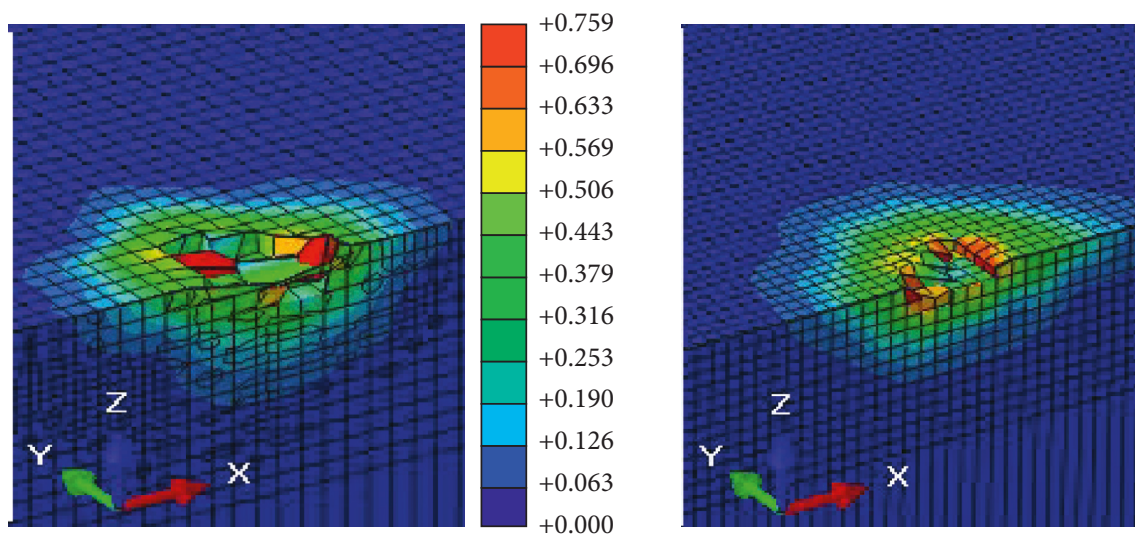

(b)

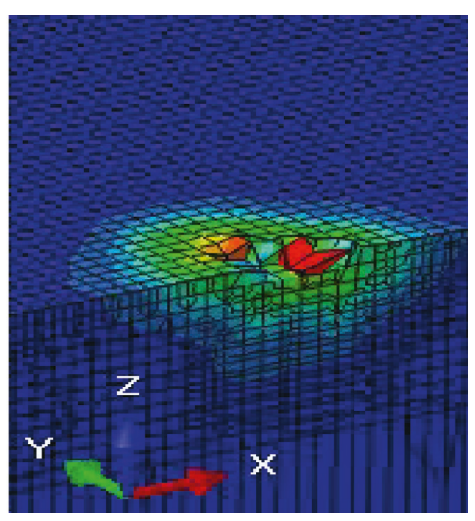

S, Mises $(\mathrm{GPa})$

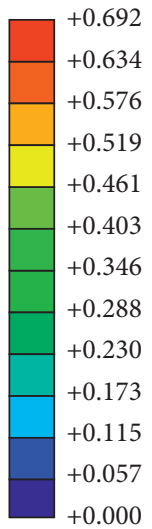

(a)

$\mathrm{S}$, Mises (GPa)

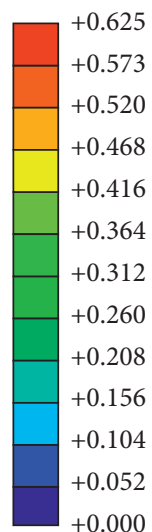

$\mathrm{S}$, Mises (GPa)
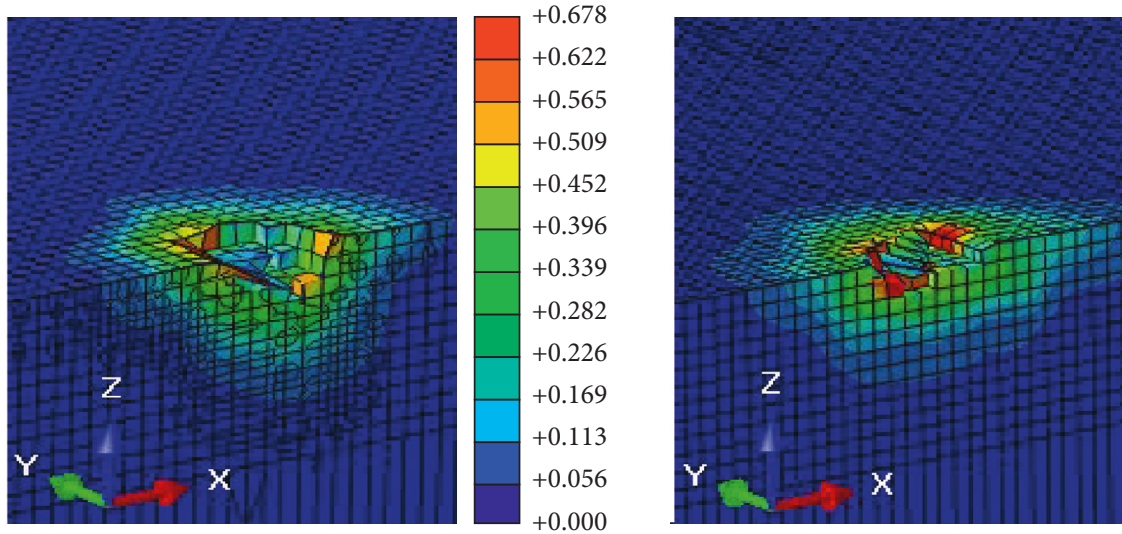

$\mathrm{S}$, Mises $(\mathrm{GPa})$

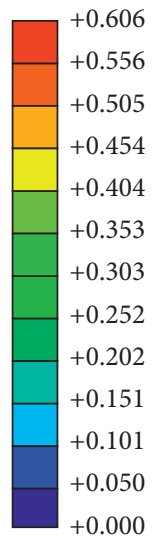

(c)

Figure 8: Continued. 
S, Mises (GPa)
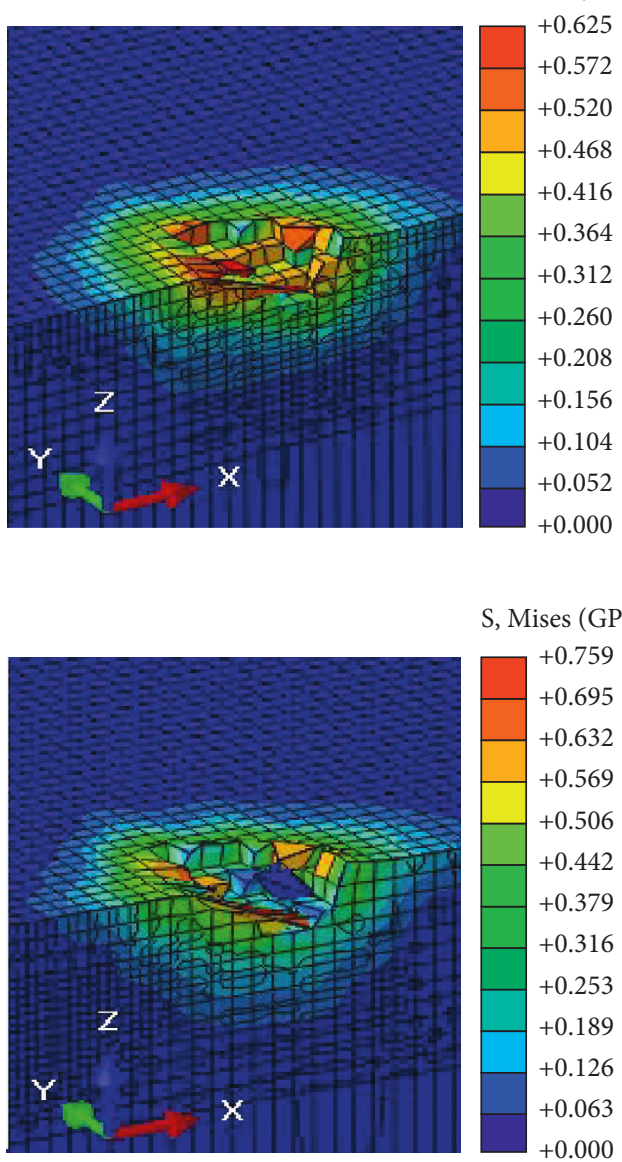

$\mathrm{S}$, Mises (GPa)

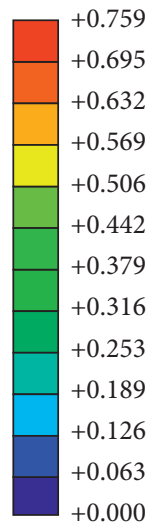

$\mathrm{S}$, Mises $(\mathrm{GPa})$
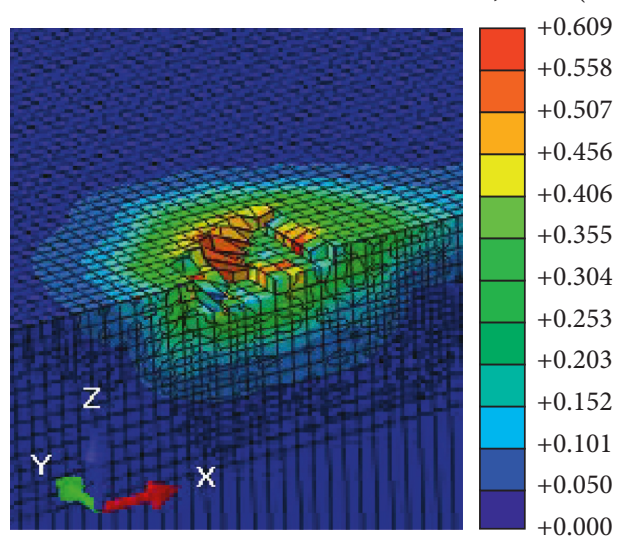

(d)

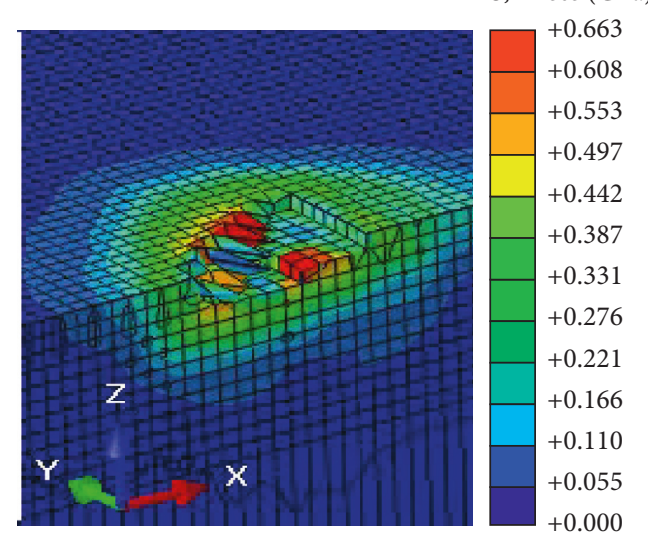

S, Mises (GPa)

(e)

Figure 8: Stress contour of the target at different impact velocities: (a) $10 \mathrm{~m} / \mathrm{s}$, (b) $12.5 \mathrm{~m} / \mathrm{s}$, (c) $15 \mathrm{~m} / \mathrm{s}$, (d) $17.5 \mathrm{~m} / \mathrm{s}$, and (e) $20 \mathrm{~m} / \mathrm{s}$ (the left figures are $30^{\circ}$ and the right figures are $75^{\circ}$ ).

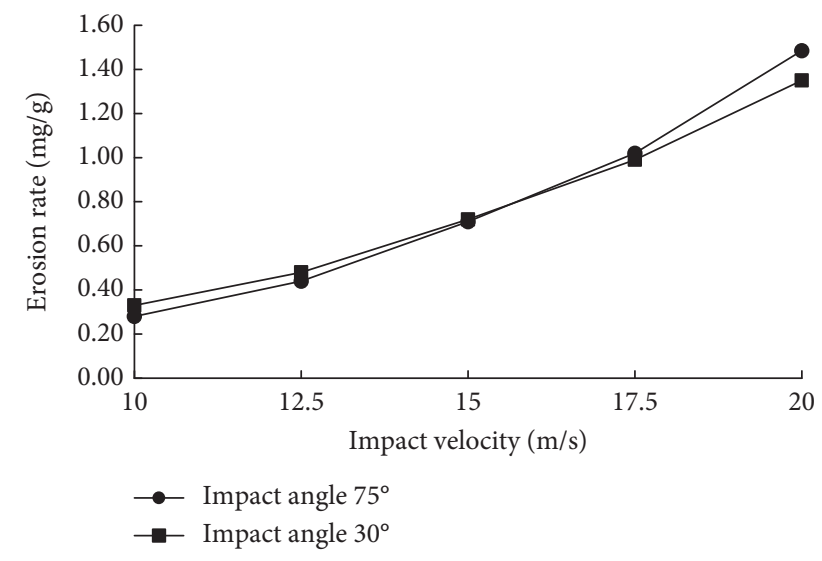

FIGURE 9: Effect of impact velocity on the erosion rate.

model is larger when the impact angle is lower than $30^{\circ}$. The biggest difference between the two models is that the predicted value of the Finnie model decreases rapidly after the impact angle is higher than $30^{\circ}$, while the erosion rate decreases slowly when the impact angle is larger. Many scholars believe that the Finnie model has good prediction

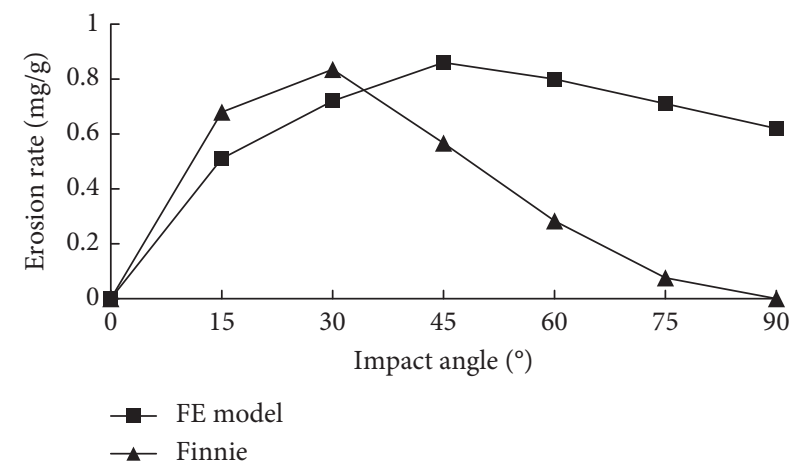

FIgURE 10: Comparison of simulation results with the Finnie model.

ability at the low impact angle, while the prediction error of the erosion rate at the high impact angle is larger $[1,4,10]$. The variation trend of the simulation curve in the figure is close to the Finnie model at the low impact angle, and the numerical difference is very small. This proves again the validity of finite element simulation, and the development trend of the simulation curve at the high impact angle is closer to reality. 
3.4. Effect of Particle Diameter. Erosion-related parameters, such as particles equivalent diameter of $50 \mu \mathrm{m}, 120 \mu \mathrm{m}$, $160 \mu \mathrm{m}$, and $200 \mu \mathrm{m}$; particle shape of tetrakaidecahedron; density of $2600 \mathrm{~kg} / \mathrm{m}^{3}$; impact speed of $15 \mathrm{~m} / \mathrm{s}$; and impact angle of $45^{\circ}$, are selected in this article. Figure 11 shows the stress contour of the section after the impact by four kinds of particles with different equivalent diameters. It can be seen from the figure that with the increase of equivalent diameters of particles, more and more elements are deleted.

Figure 12 shows the trend of erosion rate with the increase of particle diameter. It can be seen that when the particle diameter is $50 \mu \mathrm{m}$, the minimum erosion rate is $0.38 \mathrm{mg} / \mathrm{g}$, and when the particle diameter is $200 \mu \mathrm{m}$, the maximum erosion rate is $1.2 \mathrm{mg} / \mathrm{g}$. When the diameter of particles increases from $50 \mu \mathrm{m}$ to $160 \mu \mathrm{m}$, erosion rate increases rapidly. When the diameter of particles increases from $160 \mu \mathrm{m}$ to $200 \mu \mathrm{m}$, the erosion rate changes gently. The rule that the erosion rate increases rapidly first and then tends to be stable with the increase of particle diameter has been mentioned by other scholars $[16,17]$.

The reason for the erosion rate tending to be a constant value with the increase in particle diameter is that the particle mass increases with the diameter, and its kinetic energy and particle surface area also increase synchronously. However, the growth rate of the deleted mass on the surface of the target material could not keep up with the growth rate of the particle mass, so the proportion tended to be stable. On the contrary, the effect of particle size may affect the impact response of the target material, and the change of the hedging corrosion rate also has an effect.

3.5. Effect of Particle Shape. In order to study the effect of particle shape on the erosion characteristics of target, spherical, tetrahedral, and triangular prism shapes were set from blunt to sharp, and the effects of the impact angle, impact velocity, and particle equivalent diameter on the erosion rate were simulated separately.

The results for tetrahedral particles are shown in Section 3.3 in this article. The erosion results of a sharp triangular prism and spherical particles at different impact angles are shown in Figure 13. The equivalent diameter of particles is $120 \mu \mathrm{m}$, and the impact speed is $15 \mathrm{~m} / \mathrm{s}$. It can intuitively be seen that the failure and deletion of elements occur at all angles due to the erosion of the triangular pyramid, while the failure and deletion of elements occur only at $45^{\circ}$ due to the spherical particles.

Figure 14 shows the variation of the erosion rate with the impact angle of three different shaped particles with an equivalent diameter of $120 \mu \mathrm{m}$ at a velocity of $15 \mathrm{~m} / \mathrm{s}$. It can be seen from the figures that the change trend of the erosion rate curves of the three shape particles is about the same. The spherical particles are special, when the impact angles are $15^{\circ}, 60^{\circ}$, and $75^{\circ}$ and erosion rate is 0 . When the impact angle is $45^{\circ}$, the corresponding erosion rate of each shape particle reaches the maximum value, which indicates that the impact damage of the particles on the 20\# steel target is the most serious when the impact angle is $45^{\circ}$. Comparing the influence of particle shape, it is found that the severity of impact damage on the target is triangular prism, tetrakaidecahedron, and sphere in descending order, which indicates that the sharper the particles are, the greater the impact damage is, which accords with the erosion characteristics of plastic materials

Figure 15 shows the statistical erosion rate of the target impacted, respectively, by the triangular prism particles and spherical particles with an equivalent diameter of $120 \mu \mathrm{m}$, impact angle $30^{\circ}$, and velocity of $10 \mathrm{~m} / \mathrm{s}$ to $20 \mathrm{~m} / \mathrm{s}$. It can be seen that the erosion rates of triangular prism particles and tetrakaidecahedron particles increase rapidly with increasing velocity. The velocity indices are 2.31 and 2.04, respectively. The erosion rate is 0 of spherical particles when the impact velocity is less than $15 \mathrm{~m} / \mathrm{s}$, and the erosion rate increases rapidly when the velocity is greater than $15 \mathrm{~m} / \mathrm{s}$.

The variation of the erosion rate of different shape particles with different equivalent diameters is shown in Figure 16. It can be seen from the figure that the curve corresponding to the triangular prism and the tetrakaidecahedron has the same trend, and the erosion rate is first increased rapidly and then tends to be stable, while the sphere shows a tendency to increase first and then decrease, and the erosion rate is much smaller than that of sharp particles.

\subsection{Influence of Stress Interference on Erosion Behavior}

3.6.1. Particle Random Impact Model. Natural gas gathering pipelines have small particle content, and few particles continuously impact the same position. In order to study the influence of stress interference on the impact results, it is necessary to consider the randomness of the falling points. In this paper, the random impact of particles on the surface of the material is used to study the stress interference.

The random erosion model uses spherical particles with a particle diameter of $120 \mu \mathrm{m}$, a density of $2600 \mathrm{~kg} / \mathrm{m}^{3}$, an impact velocity of $15 \mathrm{~m} / \mathrm{s}$, and an impact angle of $45^{\circ}$. In the simulation, 10 layers of particles are generated, and the height difference between layers is $121 \mu \mathrm{m}$. Given five particles in each layer, the particle position is determined by using the random function to ensure that the spacing between particles is not less than particle diameter. As in the previous six-particle model, there is no contact between particles, and the finite element mesh of the stochastic impact model is obtained as shown in Figure 17.

3.6.2. Stress Interference Analysis. Figure 18 shows the stress contour distribution of the surface after 50 spherical particles randomly impacting the target. It can be seen from the figure that the particles with similar falling points show obvious stress interference, and the maximum stress is $551.2 \mathrm{MPa}$. A large number of elements have exceeded the strength limit of the target and are in a failed state, while a few elements that have experienced multiple similar point impacts are deleted. Comparing the impact angle of $45^{\circ}$ and the speed of $15 \mathrm{~m} / \mathrm{s}$, the simulation results of the six-particle repeated impact at the same position show that the element is deleted when the same position is subjected to the third impact of the spherical particles, indicating cumulative 

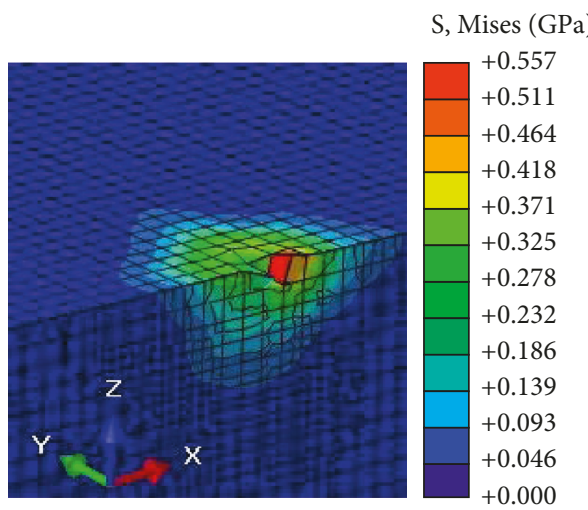

(a)

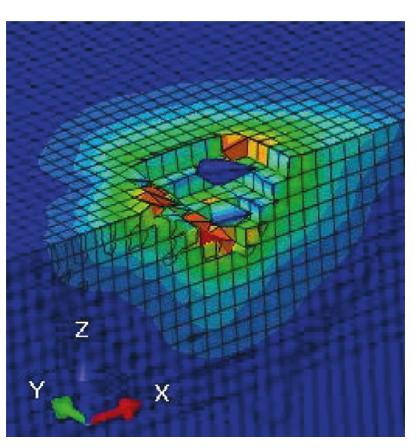

(c)

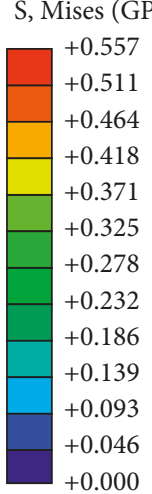

, Mises $(\mathrm{GPa})$

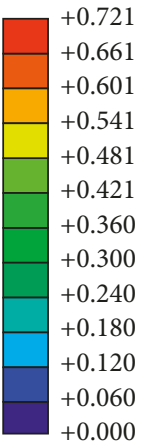

$+0.000$

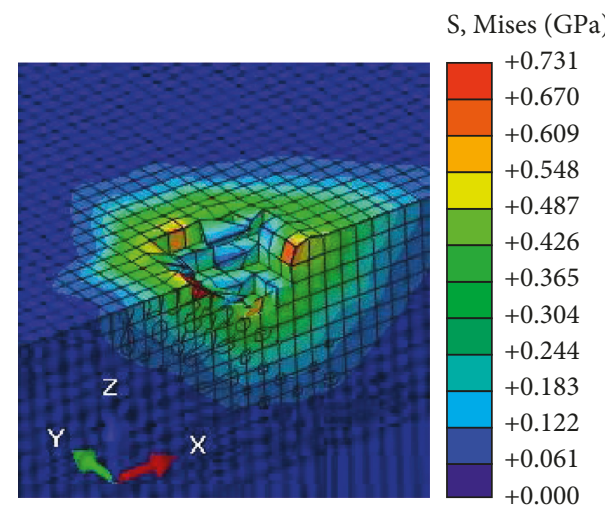

(b)

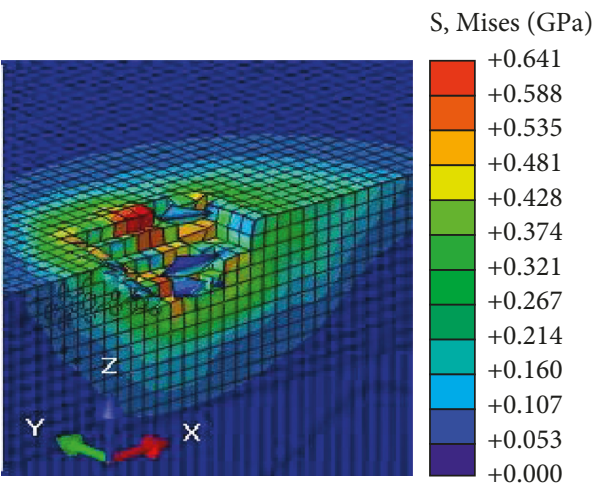

(d)

FIGURE 11: Impact stress contour impacted by tetrakaidecahedron particles with different equivalent diameters: (a) $50 \mu \mathrm{m}$, (b) $120 \mu \mathrm{m}$, (c) $160 \mu \mathrm{m}$, and (d) $200 \mu \mathrm{m}$.

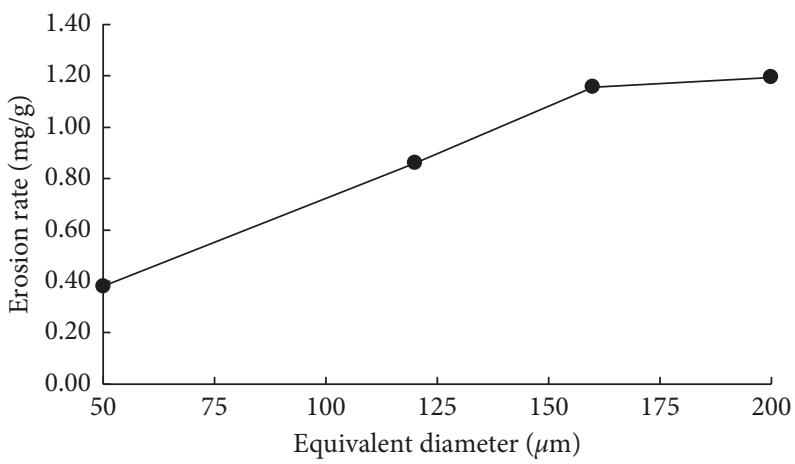

FIGURE 12: Change of the erosion rate with particle diameter.

impact damage and drop point location coincidence degree have a direct relationship. Further combined with the drop point diagram, it is found that the larger equivalent stress value appears in the places where several drop points are very close to each other, which proves that the closer the drop point position is, the more obvious the cumulative failure effect is. Therefore, it can be predicted that if the number of particles and the number of impacts continue to increase, the first place where the element is deleted must be the place where these equivalent stress values are the largest.

It can be seen from the figure that although a few point position is relatively far apart, there is a clear stress communication between the falling points in the contour image, and these connected areas are indirectly affected by the particles. The force is sufficient to cause plastic deformation of the element therein, which confirms the existence of stress interference. PJ Woytowitz believes that the stress interference damage increases first and then decreases with the increase of the distance of the falling point. When the ratio of the distance between the falling point and the particle radius is around 0.125 , the stress interference is the strongest [18].

Figures 19(a)-19(c) correspond to the ZX plane, cross section of $Y=-110 \mu \mathrm{m}, Y=-60 \mu \mathrm{m}$, and $Y=0 \mu \mathrm{m}$, 
$\mathrm{S}$, Mises $(\mathrm{GPa})$
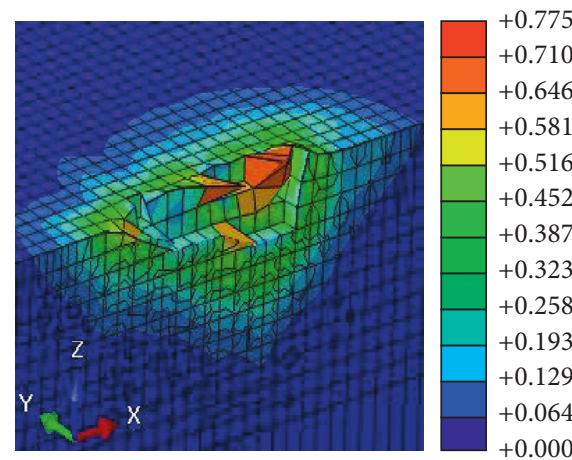

$\mathrm{S}$, Mises $(\mathrm{GPa})$
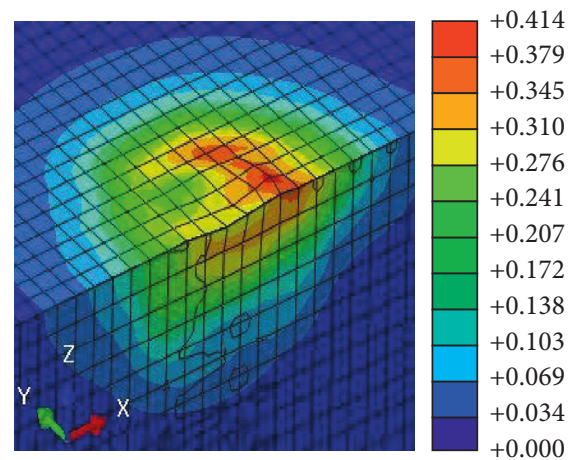

(a)

S, Mises $(\mathrm{GPa})$
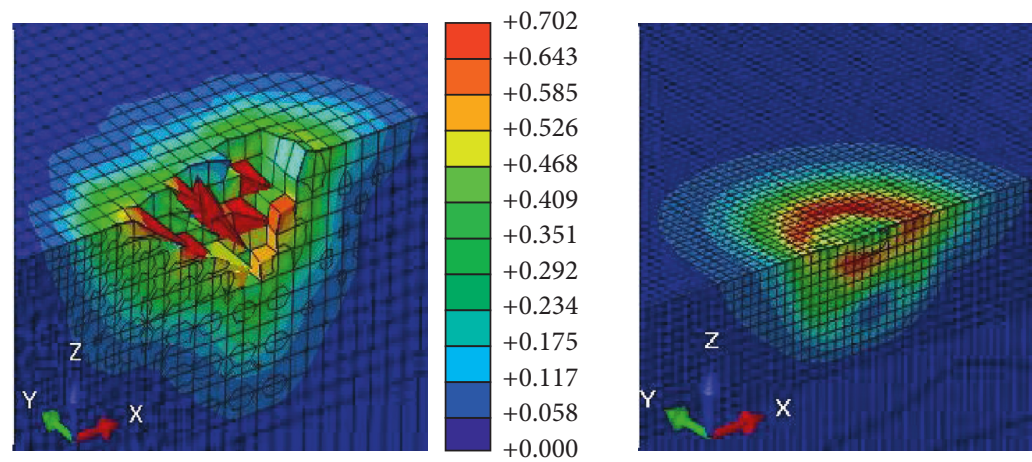

$\mathrm{S}$, Mises (GPa)

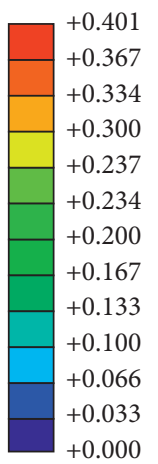

(b)

$\mathrm{S}$, Mises $(\mathrm{GPa})$
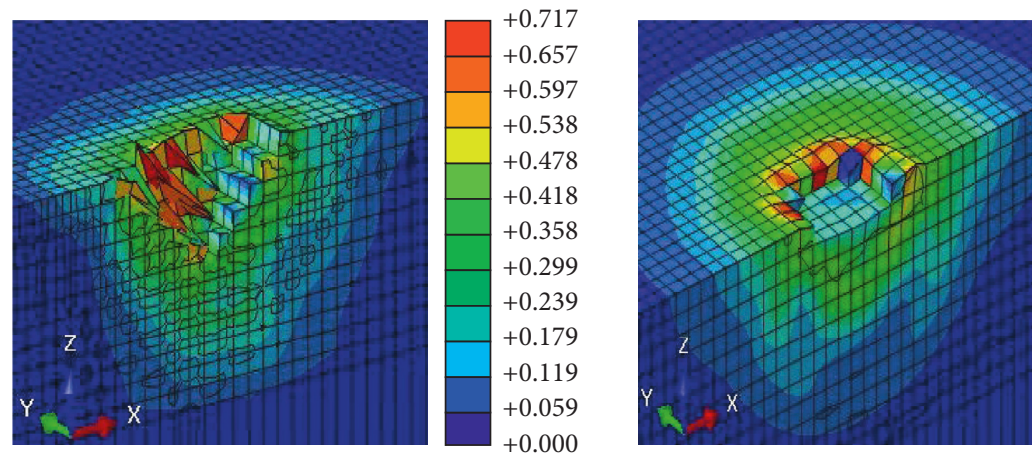

S, Mises (GPa)

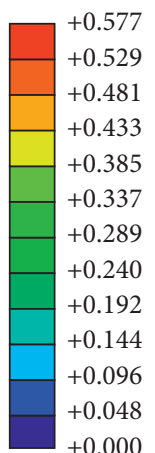

(c)

$\mathrm{S}$, Mises (GPa)
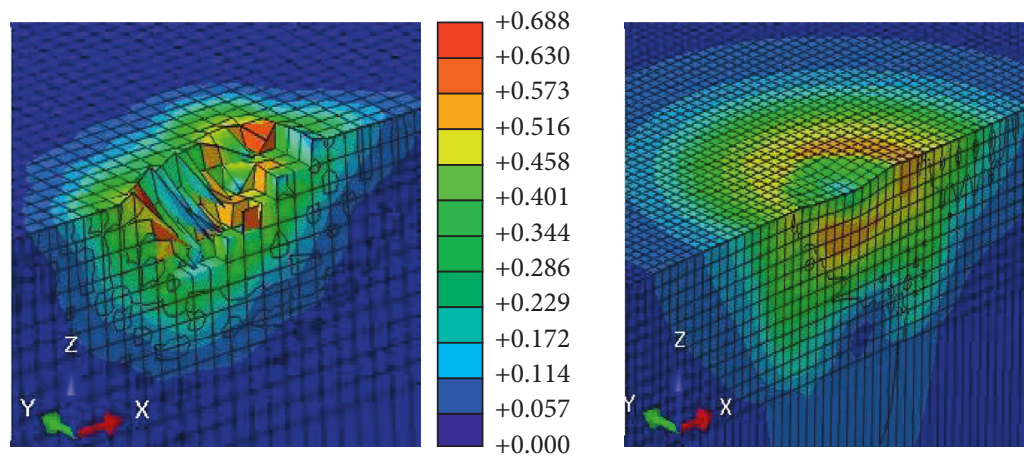

$\mathrm{S}$, Mises $(\mathrm{GPa})$

(d)

Figure 13: Continued. 
S, Mises (GPa)
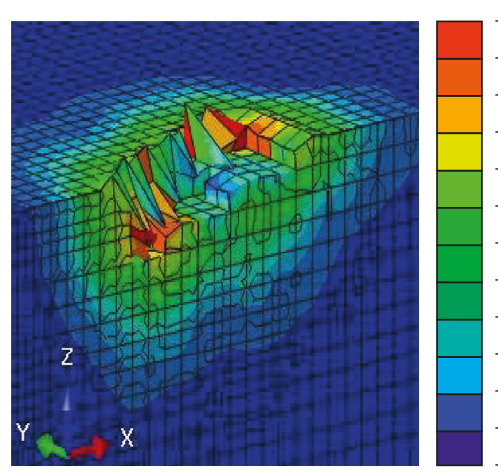

$+0.667$

$+0.611$

$+0.556$

$+0.500$

$+0.444$

$+0.389$

$+0.333$

$+0.278$

$+0.222$

$+0.166$

$+0.111$

$+0.055$

$+0.000$

S, Mises (GPa)

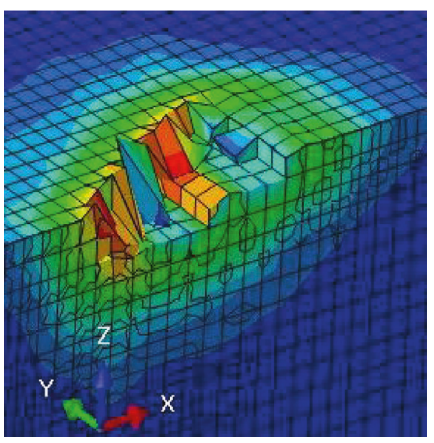

$\mathrm{S}$, Mises (GPa)
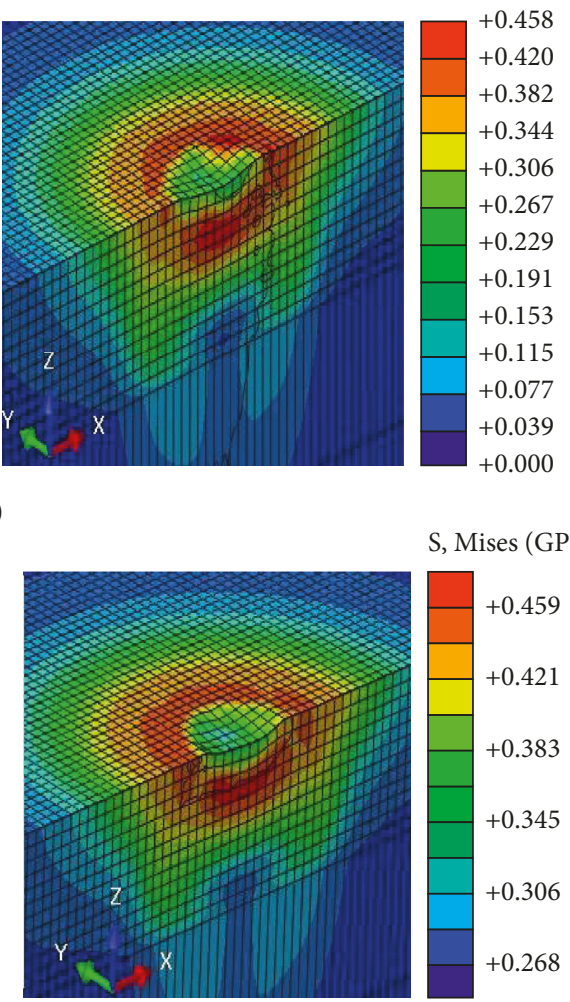

S, Mises $(\mathrm{GPa})$

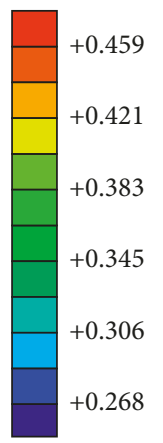

(f)

Figure 13: Impact stress contour impacted by multiparticles at different impact angles: (a) $15^{\circ}$, (b) $30^{\circ}$, (c) $45^{\circ}$, (d) $60^{\circ}$, (e) $75^{\circ}$, and (f) $90^{\circ}$ (the left figures are of triangular prism shape, and the right figures are of spherical shape).

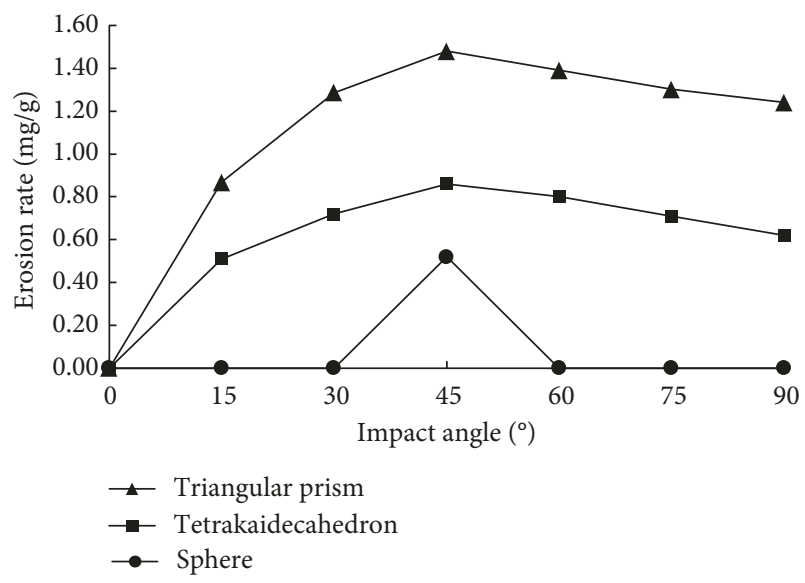

FIGURE 14: Effect of the impact angle on the erosion rate.

respectively (the specific position can be referred to the ordinates of Figure 17(a)). As shown in Figure 19, the four falling points on the left side in (a) are relatively close, with the spacing less than $10 \mu \mathrm{m}$, the individual elements have been deleted, and the maximum downward influence depth is $15 \mu \mathrm{m}$, with strong stress interference. In (b), the distance between the three falling points on the right side is about $20 \mu \mathrm{m}$, and the maximum influence depth is

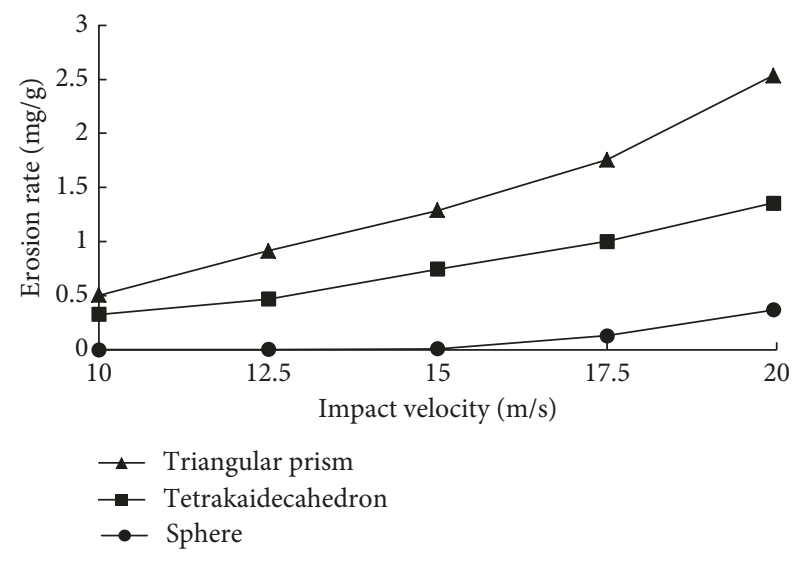

FIGURE 15: Effect of impact velocity on the erosion rate.

$12 \mu \mathrm{m}$, and the stress interference is obvious. In (c), the spacing between the falling points exceeds $60 \mu \mathrm{m}$, and the maximum influence depth is not more than $9 \mu \mathrm{m}$, and it is basically free from stress interference. Therefore, for particles with an equivalent diameter of $120 \mu \mathrm{m}$, it can be considered that when the ratio between the distance of falling point and particle radius exceeds 0.16 , the stress interference will obviously aggravate the erosion damage of particles to the target. 


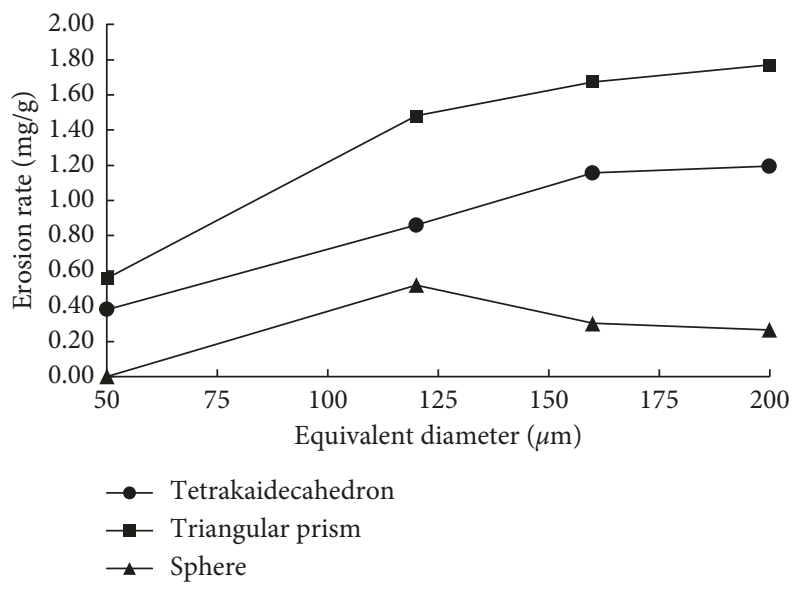

Figure 16: Effect of particle diameters on the erosion rate.

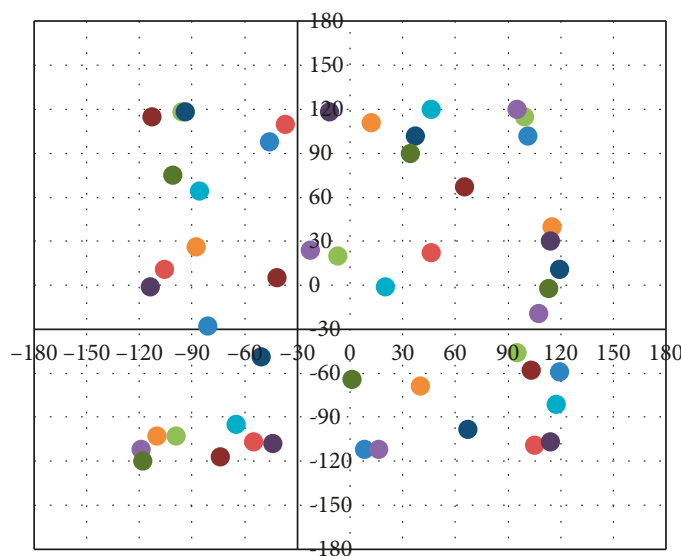

- Layer 1

- Layer 2

Layer 3

Layer 6

- Layer 7
- Layer 4

Layer 5

(a)

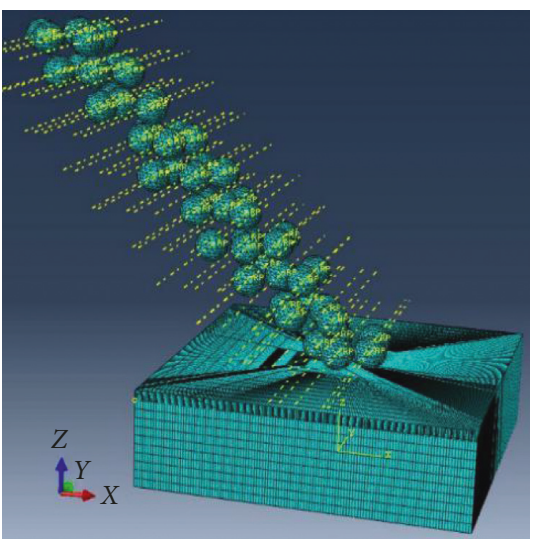

(b)

Figure 17: Random particle model and location of the drop. (a) Drop location map. (b) Random impact model grid.
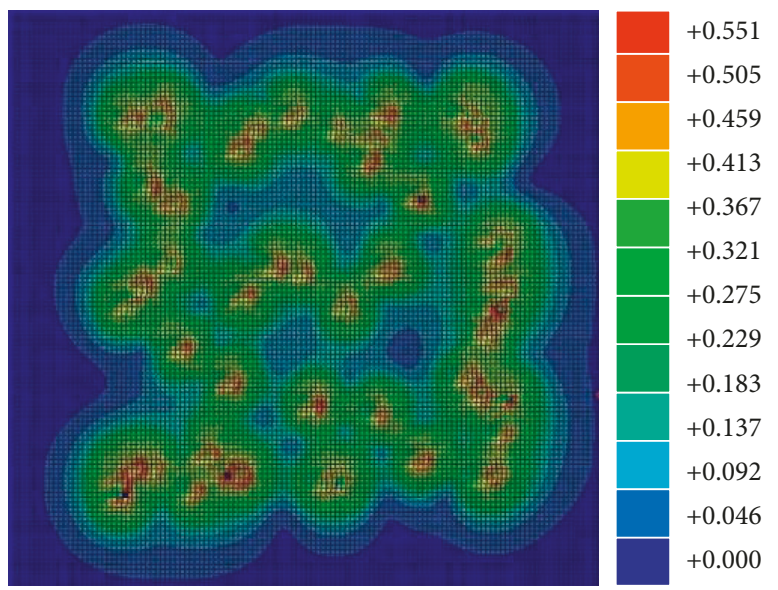

FIGURE 18: Stress contour impacted randomly by 50 spherical particles. 


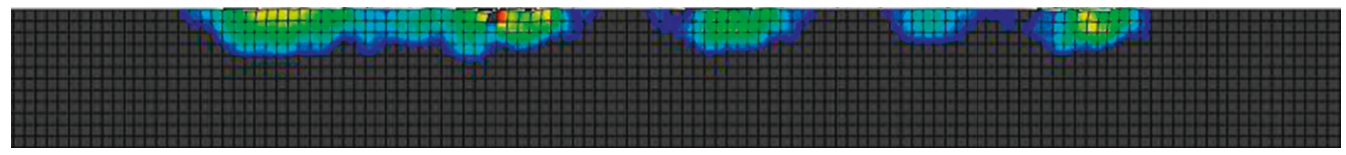

(a)

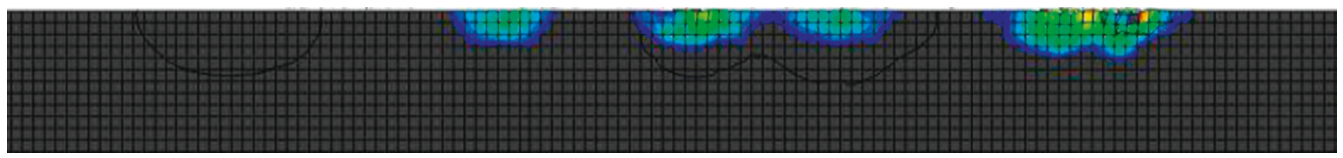

(b)

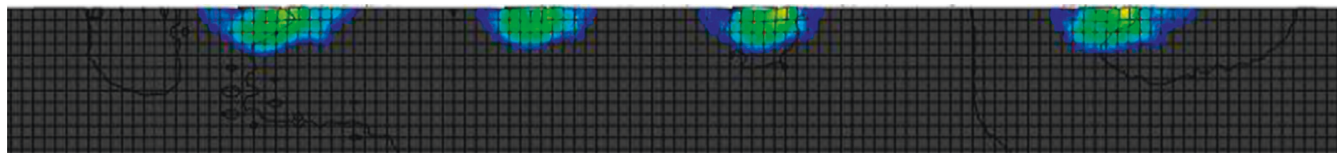

(c)

Figure 19: Stress contour result after filtering ( $>258 \mathrm{MPa}$ ) on $Z X$ plane cross section: (a) $Y=-110 \mu \mathrm{m}$, (b) $Y=-60 \mu \mathrm{m}$, and (c) $Y=0 \mu \mathrm{m}$.

\section{Conclusion}

(1) According to the working conditions of natural gas gathering pipelines, the 20\# steel erosion dynamics model based on the finite element method was established. The Johnson-Cook plasticity and failure model were used to characterize the stress, strain, and failure behavior. The simulation results are in agreement with the experimental results.

(2) The variation of kinetic energy of impact particle at different angles was obtained. It was found that the main effect of particle on the target is microcutting at the low impact angle. The kinetic energy loss tends to increase first and then decrease with the increase of the impact angle, and the contact time between particle and target decreases with the increase of the impact angle.

(3) The effects of the impact angle, impact velocity, particle size, and particle shape on the impact stress distribution and erosion failure rate of the material were obtained by simulation. Compared with the empirical model and experimental results, the simulation results show a high degree of rationality.

(4) The stress interference research model under random drop impact conditions is established to obtain the surface stress distribution law under the impact of adjacent particles. When the ratio of the drop distance to the particle radius exceeds 0.16 , stress interference will significantly aggravate the erosion damage of the target.

\section{Data Availability}

The data used to support the findings of this study are available from the corresponding author upon request.

\section{Conflicts of Interest}

The authors declare that they have no conflicts of interest.

\section{Acknowledgments}

The authors would like to acknowledge the funding support by the Open Fund of State Key Laboratory of Oil and Gas Reservoir Geology and Exploitation (Southwest Petroleum University) (Grant no. PLN1520) and Southwest Petroleum University innovation fund project (Grant no. X151518KCL12).

\section{References}

[1] D. Aquaro and E. Fontani, "Erosion of ductile and brittle materials," Meccanica, vol. 36, no. 6, pp. 651-661, 2001.

[2] S. Y. Luo, Experimental Research on Erosion and Wear of the Elbow of Natural Gas Pipeline, Southwest Petroleum University, Chengdu, China, 2017.

[3] J. Liu, W. BaKeDaShi, Z. Li et al., "Effect of flow velocity on erosion-corrosion of 90-degree horizontal elbow," Wear, vol. 376-377, pp. 516-525, 2017.

[4] G. C. Pereira, F. J. De Souza, and D. A. De Moro Martins, "Numerical prediction of the erosion due to particles in elbows," Powder Technology, vol. 261, no. 7, pp. 105-117, 2014.

[5] Y. Fu and J. Wang, "Experimental and computational failure analysis of flow erosion on new throttle in gas drilling," $\mathrm{Pe}$ troleum \& Coal, vol. 57, no. 3, pp. 246-252, 2015.

[6] Q. B. Nguyen, D. N. Nguyen, R. Murray et al., "The role of abrasive particle size on erosion characteristics of stainless steel," Engineering Failure Analysis, vol. 97, pp. 844-853, 2019.

[7] S. K. Wee and Y. J. Yap, "CFD study of sand erosion in pipeline," Journal of Petroleum Science and Engineering, vol. 176, pp. 269-278, 2019.

[8] D. Lv, Z. Lian, and T. Zhang, "Study of cavitation and cavitation erosion quantitative method based on image processing technique," Advances in Civil Engineering, vol. 2018, Article ID 5317578, 10 pages, 2018.

[9] Y.-F. Wang and Z.-G. Yang, "A coupled finite element and meshfree analysis of erosive wear," Tribology International, vol. 42, no. 2, pp. 373-377, 2009.

[10] M. Takaffoli and M. Papini, "Finite element analysis of single impacts of angular particles on ductile targets," Wear, vol. 267, no. 1-4, pp. 144-151, 2009.

[11] M. Takaffoli and M. Papini, "Material deformation and removal due to single particle impacts on ductile materials using smoothed particle hydrodynamics," Wear, vol. 274-275, pp. 50-59, 2012. 
[12] M. Takaffoli and M. Papini, "Numerical simulation of solid particle impacts on Al6061-T6 part I: three-dimensional representation of angular particles," Wear, vol. 292-293, pp. 100-110, 2012.

[13] Z. G. Liu, S. Wan, V. B. Nguyen, and Y. W. Zhang, "A numerical study on the effect of particle shape on the erosion of ductile materials," Wear, vol. 313, no. 1-2, pp. 135-142, 2014.

[14] X. W. Dong, G. R. Liu, Z. Li, and W. Zeng, "A smoothed particle hydrodynamics (SPH) model for simulating surface erosion by impacts of foreign particles," Tribology International, vol. 95, pp. 267-278, 2016.

[15] N. Kumar and M. Shukla, "Finite element analysis of multiparticle impact on erosion in abrasive water jet machining of titanium alloy," Journal of Computational and Applied Mathematics, vol. 236, no. 18, pp. 4600-4610, 2012.

[16] M. S. ElTobgy, E. Ng, and M. A. Elbestawi, "Finite element modeling of erosive wear," International Journal of Machine Tools and Manufacture, vol. 45, no. 11, pp. 1337-1346, 2005.

[17] S. Yerramareddy and S. Bahadur, "Effect of operational variables, microstructure and mechanical properties on the erosion of Ti-6Al-4V," Wear, vol. 142, no. 2, pp. 253-263, 1991.

[18] P. J. Woytowitz and R. H. Richman, "Modeling of damage from multiple impacts by spherical particles," Wear, vol. 233-235, pp. 120-133, 1999. 


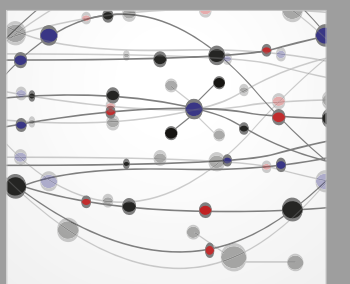

The Scientific World Journal
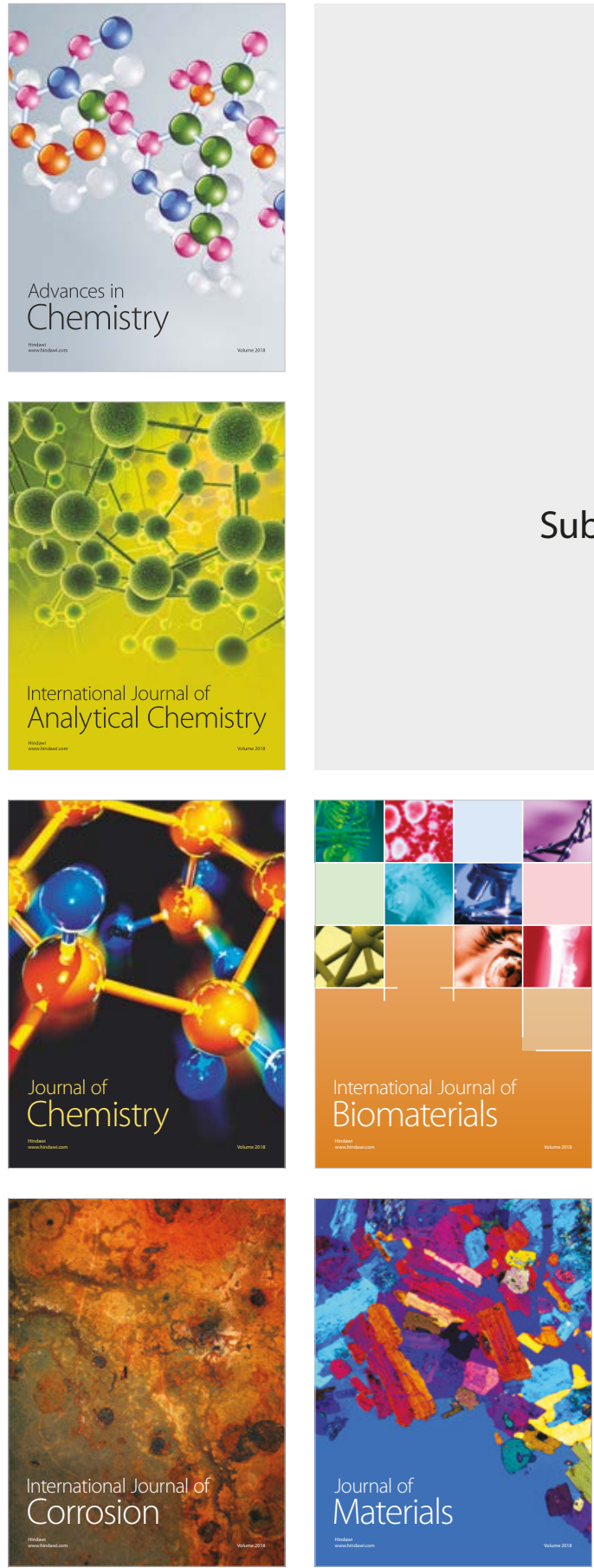

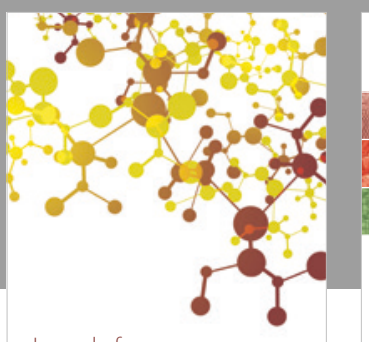

Journal of

Applied Chemistry
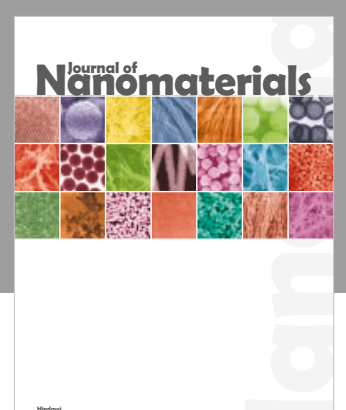

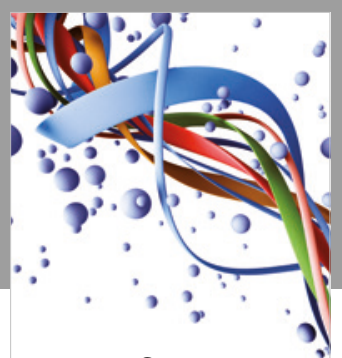

Scientifica

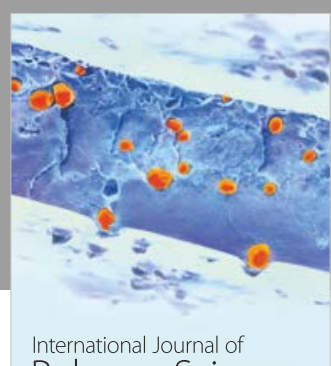

Polymer Science

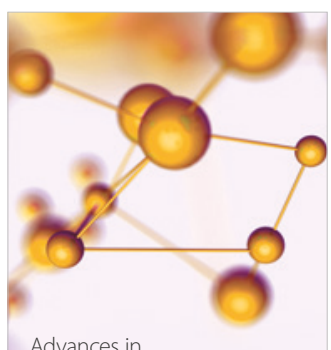

Physical Chemistry
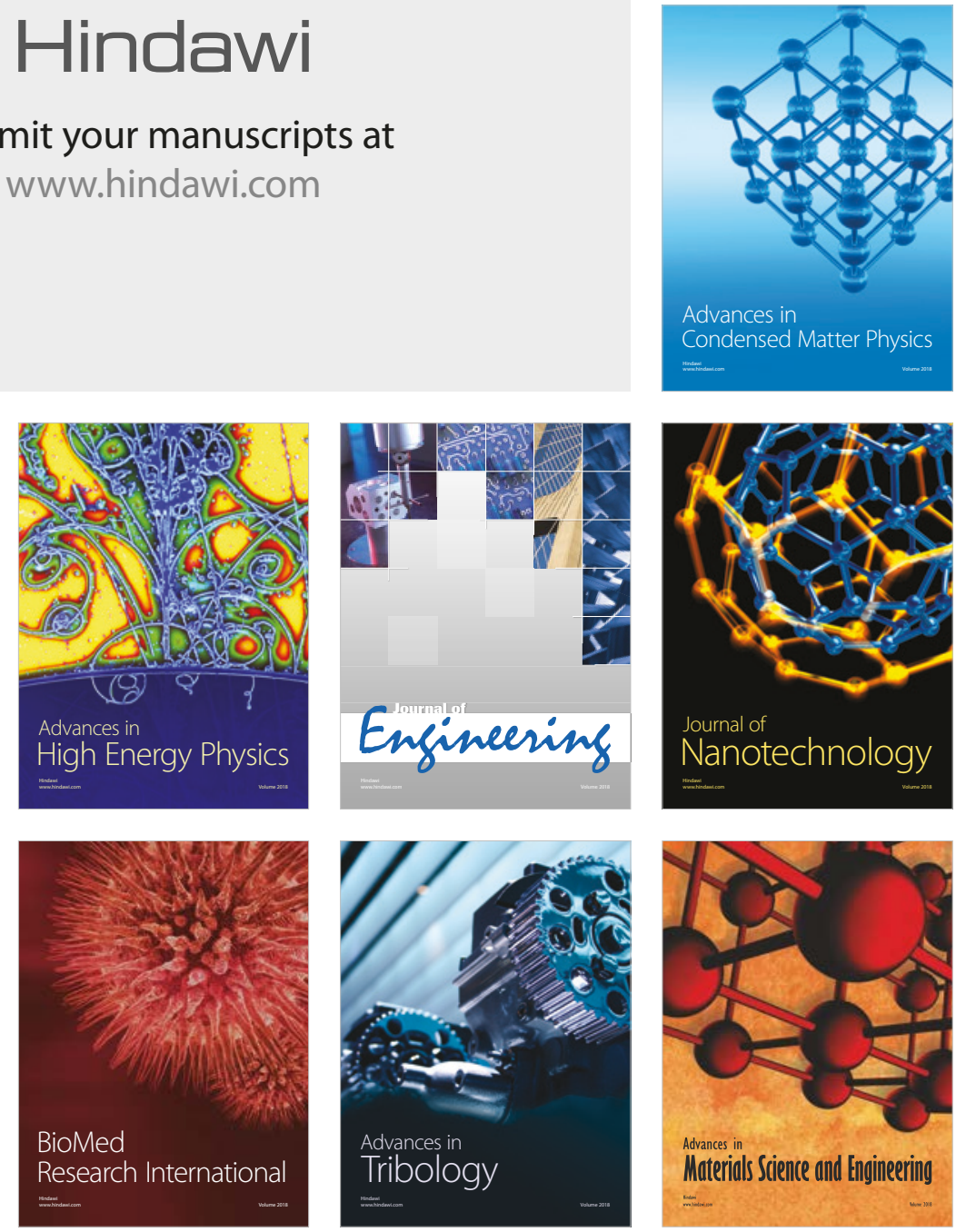